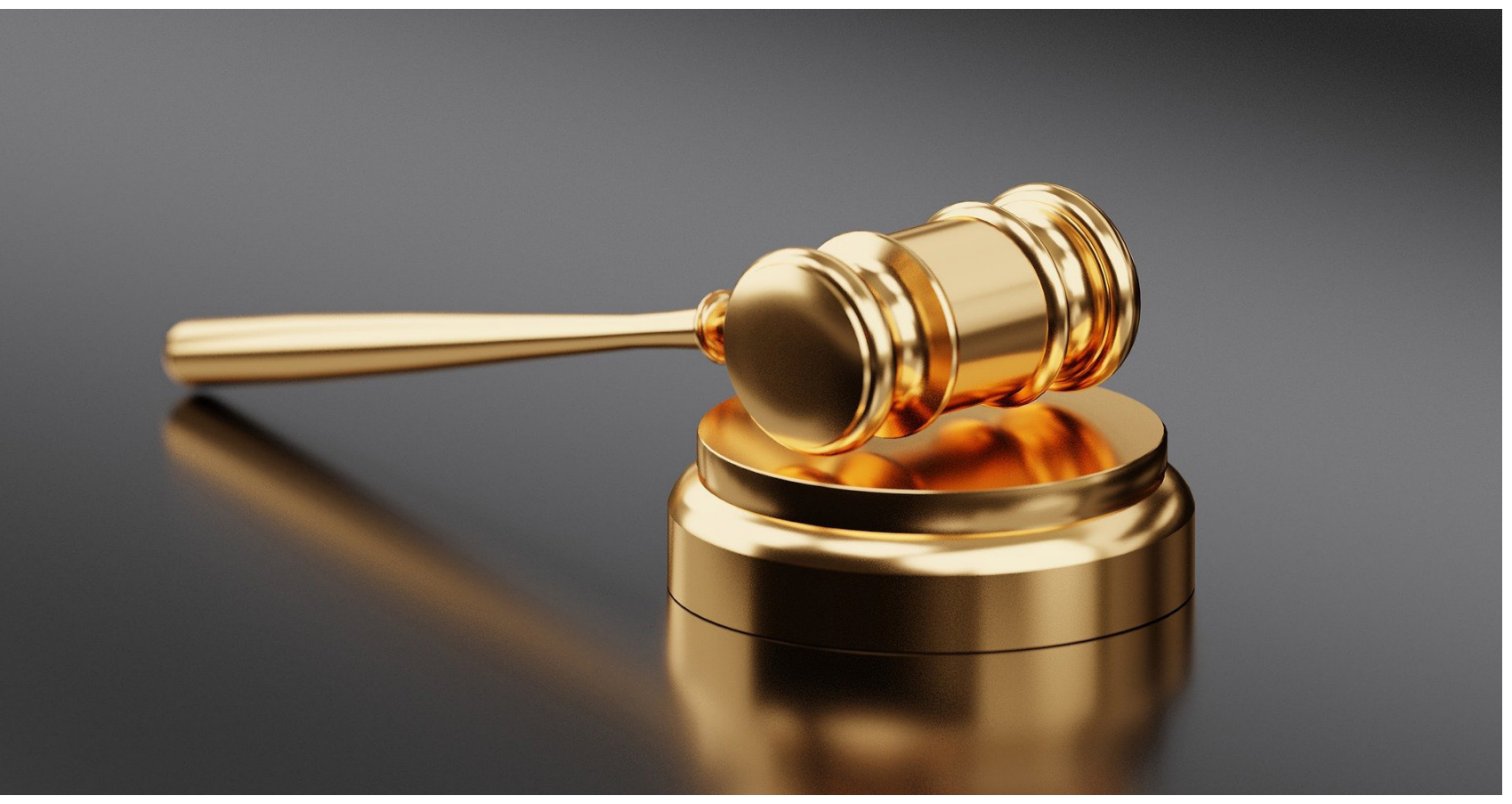

\title{
La indemnización de perjuicios inmateriales en materia de privación injusta de la libertad en la jurisprudencia de unificación del Consejo de Estado
}

Indemnification of immaterial damages in matter of unfair deprivation of freedom in the unification jurisprudence of the council of state. 


\section{Resumen}

La Privación Injusta De La Libertad, (en adelante P.I.J.D.L.), es un tema de gran relevancia en la práctica del derecho administrativo, puesto que consiste en una grave violación al derecho fundamental a la libertad personal. Es un tema que ha tenido un amplio desarrollo jurisprudencial, sobre todo a raíz de la constitución de 1991, y de la fórmula de Estado social de derecho, debiendo cumplir con procedimientos más estrictos y garantistas al momento de privar a cualquier colombiano de su libertad. Se usó el método de investigación cualitativa, hermenéutica, y será de tipo descriptiva, dado que llevaremos a cabo un estudio de la jurisprudencia del C.D.E., y especialmente la indemnización de perjuicios inmateriales. Este método permitirá abordar de una manera correcta el problema de investigación y ayudará a cumplir con los objetivos, acercando también al lector a una comprensión del problema bajo estudio. Como resultado se obtuvo una propuesta con criterios mixtos, es decir, objetivos y subjetivos, que le permitan al juez determinar de una manera precisa una indemnización similar o armónica ante casos similares, como la única posibilidad de respetar los derechos constitucionales de las víctimas de P.I.J.D.L.

Palabras clave: Privación Injusta, libertad, victima, Perjuicio Inmaterial, daño moral, responsabilidad del Estado.

\section{Abstract}

Unfair Deprivation of Liberty (hereinafter referred to as I.J.D.L.) is an issue of great relevance in the practice of administrative law, since it consists of a serious violation of the fundamental right to personal liberty. It is a subject that has had a wide development in jurisprudence, especially as a result of the 1991 Constitution, and the formula of the social state based on the rule of law, and must comply with stricter procedures and guarantees when any Colombian citizen is deprived of his or her liberty. We used the method of qualitative, hermeneutic research, and it will be of a descriptive type, given that we will carry out a study of the C.D.E.'s jurisprudence, and especially the compensation forimmaterial damages. This method will allow us to approach the research problem in a correct way and will help to fulfill the objectives, bringing the reader closer to an understanding of the problem under study. The result is a proposal with mixed criteria, that is to say, objective and subjective, that will allow the judge to determine in a precise way a similar or harmonic compensation in similar cases, as the only possibility to respect the constitutional rights of the P.I.J.D.L. victims.

Keywords: Unfair Deprivation, Freedom, Victim, Intangible Injury, Moral Damage, Responsibility Of The State. 
La indemnización de perjuicios inmateriales en materia de privación injusta de la libertad en la jurisprudencia de unificación del Consejo de Estado

\section{0}

\section{Introducción}

Es importante, que antes de abordar el tema, sean claros algunos conceptos básicos, para una mejor comprensión del mismo. El primer concepto es la libertad, que desde el punto de vista jurídico, manifesta que, no es imperio, ni facultad proveniente de lo natural, pero si derecho. (...) Encontrarse legitimado implica la facultad de hacer o no algunas actuaciones [1]. La libertad, es un derecho fundamental, y una garantía apenas mínima luego de la abolición de la esclavitud, lograda en las revoluciones liberales, de allí su gran importancia en nuestro ordenamiento jurídico, y la misma sólo debe ser restringida en casos bastante delimitados y siempre previa una autorización legal y generalmente ordenada por una autoridad judicial.

Así la Constitución Política Colombiana establece que, "toda persona es libre. Nadie puede ser molestado (...) sino en virtud de mandamiento escrito de autoridad judicial competente, con las formalidades legales ..." [2]. Existe además un principio de afirmación de la libertad individual, establecido en el código adjetivo en materia penal, "afirmación de la libertad. (...) la privación o restricción de la libertad del imputado tienen carácter excepcional; (...) su aplicación debe ser necesaria, adecuada, proporcional y razonable frente a los contenidos constitucionales" [3].

Se conoce como P.I.J.D.L., toda restricción al derecho a la libertad ordenada por una autoridad judicial, en cumplimiento o no de los requisitos mínimos legales para que ésta proceda, que una persona no debió soportar dado que no fue encontrada culpable, por la justicia colombiana, por ende, la misma solo se puede constatar, después de que se encuentre ejecutoriada la sentencia judicial que lo absuelva. En la legislación nacional estuvo contemplada en el derogado código de procedimiento penal decreto 2700 de 1991, y fue suprimido en los códigos de procedimientos de los años 2000 y 2004 (leyes 600 y 906), en la actualidad se encuentra únicamente en la ley Estatutaria de Administración de Justicia, que establece la responsabilidad del Estado Por P.I.J.D.L. así: "ARTíCULO 68. P.I.J.D.L. Quien haya sido privado injustamente de la libertad podrá demandar al Estado reparación de perjuicios" [4].

Sin embargo, mediante dos sentencias de la Sección $3^{\mathrm{a}}$ en adelante S.T. del C. D. E., del 28 de agosto de 2013 y 28 de agosto de 2014, se ha unificado el criterio de indemnización de los perjuicios inmateriales, de manera específica, los perjuicios morales, basado en los criterios de parentesco, y del término de duración de la privación de la libertad en meses para determinar el quantum indemnizatorio.

Esta nueva jurisprudencia que adopta la S.T., en sala plena, no solo confirma el giro en la jurisprudencia del C. D. E., sino que además genera una serie de interrogantes, acerca del alcance de su aplicación y de los criterios que deben ser usados para cada caso en concreto, creando una verdadera tarifa "jurisprudencial" al crear con los criterios de parentesco y tiempo de duración de la Privación Injusta en meses, una tabla de indemnización aplicable a todos los casos que en adelante pudieran presentarse.

Lo anterior, es motivo de preocupación, si se tiene en cuenta que la indemnización de perjuicios inmateriales no necesariamente va acorde con los derechos establecidos para las víctimas de P.I.J.D.L., en la norma superior y en los tratados internacionales de Derechos Humanos, que hacen parte del Bloque de Constitucionalidad.

\section{Contexto teórico}

En la presente trabajo se evaluará la protección de los derechos constitucionales de las 
víctimas, en la jurisprudencia de unificación del C.D.E., de indemnización de perjuicios inmateriales, en materia de P.I.J.D.L.

Así mismo, se pretende determinar cuáles son los derechos constitucionales de las víctimas de P.I.J.D.L., para finalmente analizar los criterios de indemnización de perjuicios inmateriales, definidos en la unificación jurisprudencial, de cara a los derechos constitucionales de las víctimas.

El C.D.E. en la práctica aplica el principio de sostenibilidad fiscal, en desmedro de los derechos a la indemnización integral de las víctimas. Teniendo en cuenta que esta corporación ha expedido dos sentencias de unificación al respecto, de la indemnización de perjuicios inmateriales y que está en tensión con los derechos constitucionales establecidos a las víctimas de P.I.J.D.L. por parte del Estado, formulamos planteamos el siguiente problema de investigación:

¿Están garantizados los derechos onstitucionales de las víctimas, en los criterios que permiten la indemnización de los perjuicios inmateriales en la jurisprudencia del Consejo de Estado periodo 1991-2016, en materia de Privación Injusta De La Libertad?

El objetivo de la presente investigación es evaluar la garantía de los derechos constitucionales de las víctimas, en la jurisprudencia de unificación del C. D. E., de indemnización de perjuicios inmateriales, en materia de P.I.J.D.L.

\section{Materiales y métodos}

El método de investigación es descriptivo, de corte cualitativo, dado que se llevará a cabo un estudio de la jurisprudencia del C.D.E., y especialmente la indemnización de perjuicios inmateriales. Este método permitirá abordar de una manera correcta el problema de investigación y permitirá cumplir los objetivos, propuestos acercando también al lector a una comprensión del problema bajo estudio [5]. Así mismo se utiliza la herramienta de análisis cualitativo hermenéutica, entendida como aquella que pretende transmitir, verter, explicar y englobar los contenidos y acepciones no visibles de los documentos y su entorno [5].

La hipótesis de investigación, consiste en manifestar que no se encuentran garantizados los derechos constitucionales de las víctimas en los criterios de indemnización de perjuicios inmateriales en materia de P.I.J.D.L, y como solución se hace una propuesta para la creación de unos criterios de indemnización mixtos esto es objetivos y subjetivos que permitan al juez tomar una decisión con una mayor discrecionalidad, pero sin caer en la arbitrariedad, y permitiéndole respetar los derechos constitucionales de las víctimas de P.I.J.D.L.

\section{Resultados}

El Tribunal más alto de lo Contencioso Administrativo, ha creado vía jurisprudencia, tablas de indemnización de perjuicios y ha fijado inclusive criterios para su modificación, partiendo del supuesto, que es posible indemnizar de manera armónica quienes han sufrido daño por parte del Estado, aumentando el clima de seguridad jurídica a la vez disminuyendo la condena que son una carga fuerte para el presupuesto nacional, en la práctica aplicando una regla fiscal, en desmedro de los derechos a la indemnización integral de las víctimas.

Las Sentencias de Unificación Jurisprudencial del C.D.E. han tomado especial relevancia en los últimos años debido a su poder vinculante y su poder de direccionar las posiciones jurisprudenciales como precedente por parte de los jueces y magistrados que son los inferiores jerárquicos (Aquo) de los Consejeros de Estado. La indemnización de perjuicios inmateriales en materia de P.I.J.D.L., ha evolucionado 


\section{2}

hasta el punto de fijarse unas tablas con criterios verdaderamente objetivos, similares a las usados por la ley para la indemnización por pérdida de capacidad laboral, solamente tener en cuenta este tipo de planteamientos objetivos para tomar decisiones puede llevar a fallos contradictorios y discriminatorios al tratar de medir con el mismo rasero situaciones disimiles y condicionar el prudente juicio del juez quien posee la inmediatez para resolver según su leal saber y entender, sin embargo este sacrificio comporta una mayor seguridad jurídica al saber prima facie, cual es la posible indemnización que podría ser obtenida.

Desde una perspectiva social, es muy importante, estudiar la indemnización de perjuicios en materia de P.I.J.D.L., dado que en este tipo de casos, las víctimas, son personas inocentes que tuvieron que sufrir el horror y el desprestigio que trae consigo haber sido privado de su libertad, y que ven en el Estado no un benefactor sino un enemigo, el cual les causo un daño irreparable, que en muchas ocasiones, deja secuelas físicas y sicológicas muy hondas e irreversibles, y que tratan de ser de alguna manera amainadas por parte de este mismo Estado, con una compensación en dinero, que puede hacer la diferencia entre un Estado social de derecho, o un gobierno autoritario.

Desde el punto de vista de la academia es importante resaltar que debe estudiarse los criterios para determinar la indemnización inmaterial de perjuicios en materia de P.I.J.D.L., especialmente el daño moral, toda vez que el C.D.E. adopto una decisión que comporta unos intereses que parecieran obedecer más a la necesidad de poder establecer una política fiscal efectiva, y un mejor clima de seguridad jurídica, pero que pueden ir en contravía de la proporcionalidad en la indemnización que debe realizarse a las personas privadas injustamente de su libertad, y los derechos que estos tienen consagrados en los artículos 2 y 90 de la constitución política de Colombia.

\section{Foco del Análisis}

-Introducción al concepto de P.I.J.D.L. Se entiende por P.I.J.D.L., tal y como lo define [5] es el injusto padecimiento de un asociado de una restricción a la libertad personal por parte del Estado a través de su rama jurisdiccional, sea que ésta actúe de forma correcta o no. Esta definición es la más adecuada, dado que, fija todos los elementos que estructuran el fenómeno de la Privación Injusta, como son la restricción de la libertad por parte de la rama jurisdiccional, y además determina que no es importante si la privación de la libertad estuvo ajustada o no a derecho, sin embargo, proponemos una definición más completa y explicita que sería la siguiente: La P.I.J.D.L., es la restricción a la libertad personal por parte del Estado a través de su rama jurisdiccional, que una persona no estaba en el deber jurídico de soportar, por haber sido absuelto mediante providencia judicial debidamente ejecutoriada.

La investigación tiene sustento en la teoría, de la reparación integral del daño, defendida por muchos autores entre ellos [6], quien señala: "la reparación integral supone el desagravio y la satisfacción completa, total y global del daño antijurídico irrogado".

En esta teoría se basa la hipótesis de que no necesariamente se está reparando de manera completa, a las víctimas de Privación Injusta, puesto que la indemnización basada en criterios objetivos no necesariamente, responderá a las necesidades planteadas en un caso concreto, siendo una obligación del abogado demostrar el perjuicio en un régimen que se supone objetivo, y además de ello, imponiendo una carga adicional al fallador para apartarse del precedente de su superior jerárquico lo que no ocurriría en otra clase de procesos de reparación directa. Esta teoría, ha sido acogida por el C.D.E., en algunos fallos, sin embargo, para el caso que nos ocupa al estar previamente tasados en la jurisprudencia sería prácticamente imposible, 


\section{3}

hacer una justa y correcta medición del daño al estar fijado previamente.

De igual manera el derecho fundamental de libertad y los derechos constitucionales de las victimas están amparados en la teoría de los derechos fundamentales que planteara "La dogmática de las garantías mínimas fundamentales es una asignatura práctica, señala, finalmente, a la argumentación razonada de unos juicios desde el deberser de garantías mínimas fundamentales determinadas previamente".

Para el presente trabajo se tiene que la restricción de la libertad, y el principio de reparación integral proveniente de dicha afectación constituyen derechos fundamentales amparados por la norma suprema, y por el derecho internacional que constituye su bloque.

Es necesario cuestionar qué significa restringir derechos fundamentales; cuando se cuestiona acerca de la limitación de garantías fundamentales debe contestarse: las limitaciones de garantías fundamentales consisten en normas que ponen limite a posturas ius - fundamentales a primera vista. Aclarando que una norma solo será una limitación de derecho fundamental al encontrarse de manera positiva en la carta magna. Al no estar contemplada, su mandato tiene la forma de una injerencia, pero no de una limitación. En el entendido que las normas son limitaciones de garantías fundamentales únicamente si están contempladas en la Constitución.

Finalmente la investigación se apoya en la teoría de la Responsabilidad Estatal por "Daño Especial", que ha sido sostenida por El Máximo Tribunal Contencioso que sostiene que Daño especial - Noción (...) Consiste en un sistema para abrogar responsabilidad, el cual no recurre a la falla, por el contrario, está basado en la actuación "legitima" que genera daño o perjuicio a los asociados los cuales por un principio de equidad y balance ante las obligaciones o cargas ante el Estado, tienen que ser reparados" [7].

Como se observa en el régimen de responsabilidad objetivo, el origen de la responsabilidad no es el dolo o la culpa, sino, por el contrario, la especial situación del administrado a quien se le exige una carga mas gravosa que la que soportan el resto de los asociados y que no puede esperarse que este soporte sin ninguna consideración.

Análisis Profundo de la Información

- Reseña histórica. Durante la egida de la norma superior de 1886 Colombia no era considerado un Estado Social de Derecho, sino solamente un Estado de Derecho, por tal motivo se aceptaba en un primer momento la irresponsabilidad del Estado en materia de P.I.J.D.L., siendo la detención preventiva una pesada carga que debían tolerar los ciudadanos.

La privación de la libertad no ha sido un concepto pacífico y ha tenido una evolución jurisprudencial a lo largo de los años, al principio el máximo tribunal fue esquivo al momento de declarar esta clase de responsabilidad [6].

Por ello en un primer momento no existieron pronunciamientos acerca de la P.I.J.D.L., dado que se consideraba que la detención preventiva era una carga más que el ciudadano debía aceptar por el hecho de convivir en una comunidad, lo cual claramente es una carga demasiado excesiva sobre todo en un país como el nuestro dónde las investigaciones pueden tomar muchos años y existe un sistema carcelario deficitario, que no cumple en muchas ocasiones las más mínimas normas de salubridad y seguridad. 
La indemnización de perjuicios inmateriales en materia de privación injusta de la libertad en la jurisprudencia de unificación del Consejo de Estado

\section{4}

Siguiendo la Estructura Planteada por [8], Podemos decir que la P.I.J.D.L., en su jurisprudencia ha tenido cuatro estadios empezando por la postura del Estado no responde por actos de carácter jurisdiccional, hasta una etapa en la que se acepta un régimen objetivo de responsabilidad estatal inclusive en los casos de aplicación del principio in dubio pro reo.

Primera etapa - periodo anterior a la Constitución de 1991. Irresponsabilidad del Estado.

Se caracteriza por que no existían condenas por P.I.J.D.L., el Estado no podía ser responsable por actuaciones de la rama jurisdiccional. Inicialmente se partía del supuesto de la ausencia de responsabilidad estatal, fundamentado en la tesis de "las cargas públicas" el ciudadano debe afrontar el juicio punitivo [9].

Segunda Etapa - Periodo en vigencia de la Constitución de 1991 y el Decreto 2700 de 1991. entrada en vigencia de la Constitución de 1991.

En vigencia de la carta del 91, se determina que el Estado si es responsable en algunos eventos de la detención injusta de las personas acusadas y que luego son absueltas se expide el decreto 2700 de 1991 código de procedimiento penal que estuvo vigente hasta el año 2000, el cual planteaba tres situaciones en las cuales debía el Estado indemnizar a las personas detenidas preventivamente durante un juicio penal.

Error Jurisdiccional. En esta Etapa la Jurisprudencia del C.D.E. establece que se puede presentar una P.I.J.D.L., por error Jurisdiccional, es decir bajo un régimen de responsabilidad subjetivo donde alguno de los agentes del Estado, ya sea funcionarios de la Fiscalía General de La Nación o de la Rama Judicial, actuando con culpa grave o dolo provocaban la privación de la libertad de manera injusta a un individuo, solo en estos casos podría existir responsabilidad estatal.

"El máximo Tribunal Contencioso, supeditó la condena por Privación Injusta a la existencia de una falla en el servicio, "error judicial" requiriendo omisión del fallador, y una vía de hecho, para poder expedir sentencia condenatoria contra el Estado [1].

Tercera etapa - periodo posterior a la Derogatoria del Decreto 2700 de 1991.

Se da un giro hacia la indemnización de perjuicios ahora fundamentado bajo el Artículo 90 superior directamente debido a la derogatoria del código de procedimiento penal, lo cual además implica un cambio en el régimen de imputación hacia el objetivo, se mantiene el arbitrio iuris, y el título de imputación en la mayoría de casos será por el título daño especial fundamentado en el desequilibrio frente a las cargas públicas.

Debido a lo antes comentado, solo cuando se daban los supuestos de la norma, podríamos hablar de Privación Injusta, la condena, depende de la absolución, que se diera por uno de los numerales del código adjetivo penal [1].

Cuarta etapa. Ampliación de los casos de Privación Injusta.

Ampliación del Criterio anterior incluyendo casos en los que inclusive se hubiere aplicado el principio de In dubio pro Reo.

El máximo tribunal contencioso, cita algunos juristas que manifestaron, que la privación de la libertad, es una carga pública que se debe aguantar de manera estoica. Empero el derecho a la libertad (personal) es fundamental en cualquier sociedad que manifieste regirse por los principios de justicia y democracia [9]. Por lo que se erigió una auténtica responsabilidad por parte del Estado 
Colombiano en materia de P.I.J.D.L., cuando un ciudadano ha sido privado de su libertad sea en detención preventiva en establecimiento carcelario, su domicilio o cualquier pena que limite su libertad, este puede y debe exigir la reparación de los perjuicios que le hubieren sido causados con tal privación.

Periodo actual - posterior a la expedición de las Sentencias de Unificación

Jurisprudencial. Con la expedición de las sentencias de unificación de la S.T. del C. D. E. y la de Sala Plena, ya pluricitadas, se da un verdadero cambio en la manera como se tasa el perjuicio inmaterial, se plantean unas tablas de punto en las que se determina específicamente bajo unos criterios objetivos las indemnizaciones que se deben dar cuando se presenten casos con supuestos de hechos similares teniendo solo en cuenta dos aspectos el parentesco y el tiempo de privación de la libertad. Además, se incluye, aunque en otras jurisprudencias, la noción de Bienes o Derechos Convencional y Constitucionalmente Amparados.

-Sentencias que constituyen la unificación jurisprudencial. Teniendo de presente que la sentencia de 28 de agosto de 2013, proferida por la Sala Plena de la S.T. del C. D. E. radicación No. 25.022- se unifica el criterio por primera vez, según el cual, teniendo en cuenta las reglas generales de la experiencia se crea una regla que se asemeja a las tablas utilizadas para la indemnización de los daños por pérdida de capacidad laboral, abrogando previamente una indemnización acorde a unos valores objetivos, que se encuentran previamente establecidos, así mismo se fijaron otros criterios para unificar la jurisprudencia en torno al daño inmaterial, que conlleva la P.I.J.D.L. La citada sentencia de unificación fue ratificada por sentencia [10], (...) en casos de P.I.J.D.L., y con apoyo en las máximas de la experiencia, haya lugar a inferir que esa situación genera dolor moral, angustia y aflicción a (...) dicho dolor moral también se genera en sus seres queridos más cercanos, (...) según las aludidas reglas de la experiencia, el dolor de los padres es, cuando menos, tan grande como el del hijo que fue privado injustamente de su libertad, cuestión que cabe predicar por igual en relación con el cónyuge, compañera o compañero permanente o estable o los hijos (...) se reiteran los criterios contenidos en la sentencia de [11].

El Máximo Tribunal Contencioso, en materia de P.I.J.D.L. , ha creado una jurisprudencia de unificación que como novedad, trae consigo, tablas de indemnización de perjuicios (tablas de punto), y además una manera de aplicarlas e inclusive criterios para aplicarlas totalmente $o$ apartarse de las mismas, creando un verdadero régimen objetivo al respecto, por tal motivo en materia de indemnización de perjuicios morales los jueces de la República de Colombia, ahora están supeditados a la aplicación de este criterio de unificación jurisprudencial, el cual es sin lugar a dudas de gran trascendencia, dado que, le resta a los operadores judiciales autonomía e independencia para proceder en cada caso concreto, sin embargo, le da a los afectados y a las entidades posiblemente condenadas una mayor seguridad acerca del quantum, de la petición en este sentido, pese a lo anterior, el C.D.E., al crear estos criterios está modificando la manera cómo se tasa el más subjetivo de todos los perjuicios.

"El daño moral" quitando al juez su natural inmediación con respecto a la prueba, creando una tarifa "jurisprudencial" que pese a estar basada en las reglas generales de la experiencia pareciera desconocer el carácter resarcitorio (mas no indemnizatorio) del daño moral, en el cual no pretende recuperarse o reintegrarse un daño sino que este bien ya lesionado de manera irreversible, se vea aplacado en su intensidad, por medio de una compensación económica, pudiendo inclusive 
La indemnización de perjuicios inmateriales en materia de privación injusta de la libertad en la jurisprudencia de unificación del Consejo de Estado

\section{6}

desnaturalizar el mismo concepto de daño moral.

Sin embargo, debe tenerse en cuenta que los anteriores no son los únicos criterios para determinar el daño moral sino que en cada caso particular y concreto es deber de las partes el probar los perjuicios que reclaman, en la práctica jurídica, hemos tenido la posibilidad de observar que estos criterios son problemáticos en casos límite, así como, la obediencia casi ciega de los jueces a la jurisprudencia de unificación, teniendo temor, en muchos casos de conceder más allá de lo que esta establece, pero teniendo pocos reparos para conceder mucho menos de lo allí establecido, especialmente, en casos en los que existía abundante material probatorio, pero operaron fenómenos tales como la prescripción procesal o el indubio pro reo.

Así cómo en estos casos, los derechos constitucionales, establecidos para las víctimas de P.I.J.D.L., por parte del Estado, podrían verse afectados por estas consideraciones realizadas por el C. D. E., en su afán de limitar el quantum de las condenas, puede que haya dejado a un lado el derecho de las víctimas a ser realmente resarcidas, a cambio de buscar una reducción de la carga fiscal por la gran cantidad de condenas que tiene el Estado Colombiano, por privar injustamente de la libertad a sus ciudadanos.

Perjuicios inmateriales. En Colombia, podemos establecer de manera clara, que existe el reconocimiento por parte de la Jurisprudencia de los perjuicios inmateriales, siendo por excelencia el daño moral el más reconocido, de esta clase de perjuicios. La definición de Daño, para poder comprender cómo se resarcen los perjuicios irrogados por el mismo:

Para [12] "daño se define como disminución que presentada en el patrimonio por la disminución de los títulos económicos que constituyen el daño material y perturbación a las emociones, a la figura del honor o legítimas afecciones daño inmaterial".

"Agregando a lo anterior, el Estado responde objetivamente y como consecuencia produce una indemnización de perjuicios (...) que no tienen valoración económica; es decir, que no comprenden la órbita patrimonial, estos son los perjuicios inmateriales, correspondiendo a una indemnización, en la que se debe reparar integralmente al individuo cuya afectación vulneró su vida, integridad o bienes" [13].

Sería entonces el perjuicio inmaterial una clase especial de Perjuicio como se explica a continuación si ponemos la indemnización desde una perspectiva compensatoria en contra de la restitutoria, de los bienes, esta se sostiene de manera ideal,(...) se define como compensación, la que se hace en dinero, o, alguna otra solicitud lógica de la víctima o por decisión de un juez, entregada a quien un bien aminore su sufrimiento, sin que importe que la reparación sea o no en dinero,(...) cualquier bien que aminore el sufrimiento,(...) sobrellevar su congojo y aliviar el sufrimiento en mejores condiciones a la afectación sentimental realizada, y llevar así a que se disminuya o desaparezca el sufrimiento causado"

Clases de Perjuicios. Los perjuicios patrimoniales o materiales se clasifican el daño emergente y el lucro cesante grosso modo, de otra parte, se encuentran los no patrimoniales o inmateriales cuya clasificación es un poco más compleja. derecho al buen nombre, el honor o la honra, el derecho a tener una familia, entre otros)" Temiendo de esta manera que las categorías de los perjuicios inmateriales son:

- Daño Moral.

- Daño a la vida en relación. (Superada)

- Alteración a las condiciones de existencia. (Superada)

- Daño a la salud. (A partir de 2011). 
- Bienes o Derechos Convencional y Constitucionalmente Amparados. Tales como, Derecho al Buen Nombre, Derecho a la Honra, Derecho a una Familia, Derecho al Habeas Data, Etcétera.

Criterios para indemnizar Perjuicios inmateriales. Sea lo primero decir que a diferencia de lo que pudiera pensarse, la P.I.J.D.L., se puede presentar en casos en los cuales el Estado ha actuado de manera totalmente legal, pese al precedente constitucional existente el cual plantea que este articulo no merece alguna tipo de objeción - que se apegue algún estamento jurídico constitucional en los art 6o, 28, 29 y 90 de la Carta [14].

La apartada posición del C.D.E., no es caprichosa, sino que, se fundamenta como ya lo hemos visto, en la prevalencia de la libertad como valor superior en cualquier sociedad que se precie de ser democrática y justa, por tal motivo, es imposible que los ciudadanos acepten sin ningún reparo la privación de la libertad si son absueltos ya sea porque no cometieron un hecho o por que el Estado no puedo desvirtuarle la presunción de inocencia.

La Arbitrio luris. Es el criterio por excelencia. para restablecer los daños inmateriales, en estos, el juez tiene absoluta libertad para establecer mediante los elementos de prueba el quantum indemnizatorio, este sistema es problemático ya que el mismo lleva a condenas muy disímiles en casos bajo supuestos de hecho muy similares. "El libre arbitrio judicial, produce que el fallo se entienda como resultado de un hombre, lo contrario a un silogismo, o un automatismo".

El criterio Objetivo. En es un criterio que se determina por factores objetivos es decir medibles y cuantificables para el caso que nos ocupa se han fijado en las jurisprudencias de Unificación unos criterios en cuanto al tiempo de duración de la privación de la libertad y el grado de parentesco.

Las reglas de la Experiencia. Según lo ha mencionado la Jurisprudencia del C.D.E., en casos de P.I.J.D.L., y apoyándose en las máximas de la experiencia, hay lugar a inferir que esa situación genera dolor moral, angustia y aflicción a las personas que por esas circunstancias hubieren visto afectada o limitada su libertad; (...) según las aludidas reglas de la experiencia, el dolor de los padres es, cuando menos, tan grande como el del hijo que fue privado injustamente de su libertad, [15].

Tablas de Indemnización. A modo de ilustración se anexa la tabla de indemnización establecida en la sentencia de Unificación Jurisprudencial C. D. E., en P.I.J.D.L. (Tabla 1)

Tabla 1. Indemnizaciones

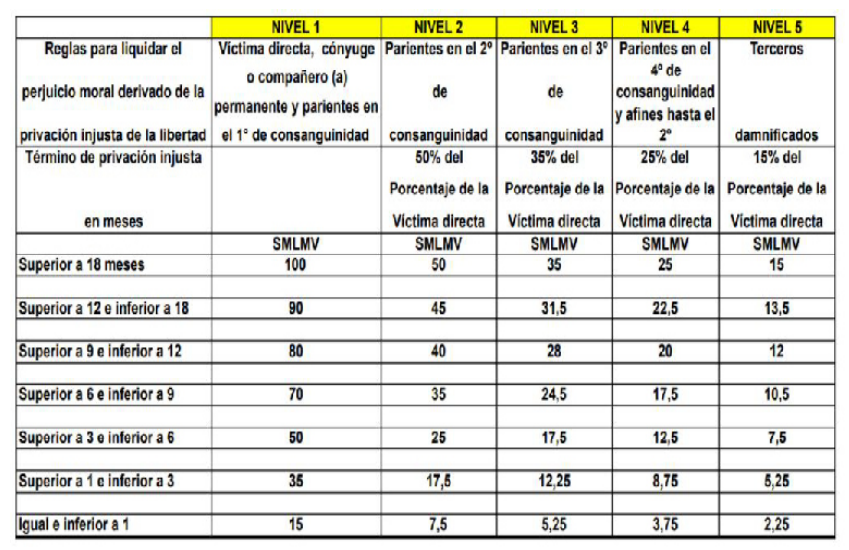

Como puede verificarse, son criterios medibles, cuantificables y que dan una mayor seguridad jurídica, pero sacrificando la capacidad del juez de alejarse de los mismos dificultando la aplicación de otros criterios cuando no se presenten casos límites o que manifiestamente se salgan de lo ordinario o de lo convencional, presentando serios desafíos para la autonomía judicial. 
La indemnización de perjuicios inmateriales en materia de privación injusta de la libertad en la jurisprudencia de unificación del Consejo de Estado

\section{8}

Los derechos Constitucionales de las víctimas. En la sentencia de Unificación Jurisprudencial de P.I.J.D.L., se omitió completamente hacer alusión al concepto de reparación integral, esto no es una actitud aislada, sino que corresponde a una posición adoptada de manera consciente, dado que, lo que se pretendió con esta unificación fue ponerle un freno a las condenas que de manera imparcial y consecuente, los jueces de instancia venían imponiendo al Estado Colombiano, por una mala administración de justicia, que es la que da cuenta de una cantidad considerable de condenas Por P.I.J.D.L. Así en el articulo el día 01 de febrero de 2016, hoy, en el saldo en rojo de la Fiscalía, ya hay orden de jueces para que se giren 477.000 millones de pesos a colombianos que perdieron su libertad.

Derecho a la reparación integral. Por lo que puede verse que la intención del Alto Tribunal Contencioso no era, precisamente la de dar una mayor protección a los derechos de las víctimas de Privación Injusta, sino que, por el contrario, fue diseñado para reducir la cantidad de la indemnización que debía pagar el Estado por este concepto. En la Constitución política de Colombia encontramos la clausula general de responsabilidad del Estado que reza: "El Estado responderá patrimonialmente por los daños antijurídicos que le sean imputables, causados por la acción o la omisión de las autoridades públicas" [2].

Además, en el ya citado articulo 28 de la constitución se establece un régimen de libertad que prohíbe su restricción salvo que obre mandato previo por escrito de autoridad competente, impone un régimen que impide al menos formalmente la violación al derecho fundamental a libertad. Para el caso de la P.I.J.D.L., sería la actuación de la rama jurisdiccional o de la Fiscalía General de la Nación las posibles causantes del daño antijuridico, sin embargo, al plantearse el régimen objetivo, en general, no se entra a repetir contra los agentes del Estado causantes del mencionado daño, siendo esta una de las razones por las cuales tal vez, es un daño que sigue ocasionándose de manera sistemática.

El daño a la salud. El Concepto de daño a la salud está contemplado por el máximo tribunal de lo contencioso de la siguiente manera:

"...el concepto de salud (...) comprende aspectos físicos y psíquicos, por lo que su evaluación será mucho más sencilla puesto que ante lesiones iguales corresponderá una indemnización idéntica 31. Por lo tanto, no es posible desagregar o subdividir el daño a la salud o perjuicio fisiológico en diversas expresiones corporales o relacionales (v.gr. daño estético, daño sexual, daño relacional familiar, daño relacional social), (...) es posible tasarlo o evaluarlo, de forma más o menos objetiva [16].

Es relevante aclarar que bajo la denominación genérica daño a la salud, se han integrado otra clase de concepto que, aunque relacionados, dogmáticamente tienen muy poco que ver con la salud, cómo es el caso del daño ala vida en relación, y la alteración de las condiciones de existencia, que antes podrían decretarse adicionales al llamado perjuicio fisiológico [16].

Bienes o Derechos Convencional y Constitucionalmente Amparados. Se encuentran establecidos en la jurisprudencia del Máximo Tribunal de lo Contencioso Administrativo, "(...) se procederá a aplicar los criterios de unificación (...) a bienes constitucional y convencionalmente amparados, en atención a que el juez administrativo, en aplicación directa del control de convencionalidad, deberá lograr el resarcimiento pleno del perjuicio $y$, principalmente, la restitutio in integrum de los derechos fundamentales conculcados. Sin embargo, vale aclarar que, si bien su reconocimiento está contemplado en la jurisprudencia del C.D.E., no se encuentra reconocido en la Sentencia de Unificación 
jurisprudencial por P.I.J.D.L., pese a que comporta, la violación a uno de los derechos fundamentales más importantes, la liberta personal, sino contra algunos bienes cómo el buen nombre, el honor, la honra, la dignidad, entre otros que podrían solicitarse al haber sido afectados por la Privación Injusta.

Normatividad Internacional indemnización a víctimas de P.I.J.D.L. En Derecho internacional solo encontramos plasmado un postulado similar al de Privación Injusta en el siguiente instrumento:

Pacto Internacional de Derechos Civiles y Políticos. "Artículo 9.5. Toda persona que haya sido ilegalmente detenida o presa, tendrá el derecho efectivo a obtener reparación." [17].

La posición de la CIDH. La CIDH, si bien no contempla una condena en especifico en contra de la P.I.J.D.L., si está facultada para dar aplicación a otros instrumentos internacionales cómo el mencionado Pacto de derechos civiles, el cual, si contempla dicha indemnización, sin embargo, este tribunal se ha pronunciado de esta manera:

“....Nadie puede ser sometido a detención o encarcelamiento por causas y métodos que -aun calificados de legales- puedan reputarse como incompatibles con el respeto a los derechos fundamentales del individuo por ser, entre otras cosas, irrazonables, imprevisibles, o faltos de proporcionalidad..." [18].

Respecto reparar víctimas de una forma integral, a las víctimas, explica [10],[19] "(...) medidas de reparación integral (...) 1) restitución, 2) rehabilitación, 3) satisfacción, 4) garantías de no repetición, 5) obligación de investigar los hechos, determinar los responsables y, en su caso, sancionar, y 6) indemnización compensatoria." Las anteriores son las clases de medidas ordenadas en pronunciamientos de la $\mathrm{CIDH}$, que contempla variados y diversos mecanismos de reparación a las víctimas para así lograr una adecuada reparación del daño que les ha sido irrogado, la jurisprudencia nacional e internacional aún distan de estar cercanas en estos conceptos y en la práctica los tribunales nacionales, no suelen conceder todas las medidas de reparación contempladas en el derecho internacional a nivel local.

\section{Análisis de los criterios objetivos:}

La Jurisprudencia de Unificación de perjuicios en materia de P.I.J.D.L., claramente expone cuales son los criterios a tener en cuanta al momento de definir la indemnización objetiva de perjuicios morales:

1. Grado de parentesco. Entendido, cómo el grado de consanguíneo, de afinidad o civil en que se encuentran las victimas directa e indirectas, estableciendo cuatro niveles, acorde a estos grados de parentesco, sumando a lo anterior las relaciones de crianza y los vínculos afectivos demostrados.

2. El tiempo de duración de la privación efectiva de la libertad. Este es establecido de manera curiosa en meses y no en días, lo cual lo vuelve un tanto problemático en casos limites, cómo hemos visto en la práctica, y supedita a siete niveles comprendidos entre un día y 18 o más meses de detención, siendo esta en establecimiento carcelario o en lugar de residencia.

\section{Discusión}

Una aplicación de criterios mixtos es necesaria y si bien las Sentencias del C.D.E. no están planteando de manera expresa criterios mixtos, esto puede observarse en las diversas sentencias de unificación que expresamente establecen que en algunos casos pueden ser desconocidos estos principios en aras 


\section{0}

de garantizar una verdadera indemnización integral algunos autores opinan que:

Los criterios objetivos adoptados por el C. D. E., son de obligado acatamiento, excepto que por motivos excepcionales el fallador tenga que apartarse asumiendo el compromiso de rigor argumentativo (...). En aplicación del principio denominado arbitrio iuris el fallador tiene que argumentar su sentencia, ¿En que se distingue esta posición de la que tendría un fallador al fundamentar que se abstiene de aplicar una tabla denominada de punto? No la tiene [15]. Discrepamos en parte de esta posición, ya que no es igual el arbitrio judicial a la separación de una tabla de punto, debido a que existe un precedente jurisprudencial y apartarse de él implica desde un punto de vista un acto de valentía y de independencia, que va en contra de la política de precedente judiciales que quiere implementar el C.D.E., además de los posibles problemas que pueda enfrentar el funcionario que vaya en contra de sus superiores jerárquicos, ante la gran égida del derecho disciplinario que en Colombia es un leviatán, creemos que es posible crear criterios subjetivos, que razonadamente permitan indemnizar de una manera armónica a los demandantes que soliciten el resarcimiento de los perjuicios inmateriales en materia de P.I.J.D.L., cuando sus supuestos de hecho sean similares.

La creación de criterios subjetivos para la indemnización de perjuicios inmateriales, tales como determinar la convivencia o no con la victima directa, el cumplimiento de la condena en establecimiento carcelario de mayor o menor complejidad, o con problemas de hacinamiento, detención en lugar de residencia, la prestancia económica, social, cultural, profesional etc., en la sociedad donde está inserto la victima directa, la afectación o perturbación del proyecto de vida, entre otras podrían ser tomadas cómo base para realizar criterios de interpretación subjetiva que permitan al juez de manera razonable, modificar los limites indemnizatorios de manera mucho mas dinámica, y permitirle que sin apartarse del precedente vinculante, garantice el derecho a la reparación integral de las víctimas, de esta manera pueda cumplir de manera adecuada a su labor sin estar expuesto a posibles sanciones disciplinarias por apartarse del precedente y regulando de manera mucho más adecuada la indemnización de perjuicios inmateriales tales cómo el daño moral, sin olvidar que resulta necesario nuevos pronunciamiento respecto de los conceptos de daño a bienes convencional y constitucionalmente amparados que resultan afectados de manera frecuente en P.I.J.D.L., cómo el buen nombre, la dignidad y la honra, además de la libertad individual, así como, el daño a la salud en general psicológica, que se produce al pasar por la terrible experiencia de una detención en establecimiento carcelario en Colombia.

\section{Conclusiones}

Las Sentencias mediante las que se hace Unificación Jurisprudencial del C.D.E., han tomado especial relevancia en los últimos años, debido a su poder vinculante y su capacidad de direccionar las posiciones jurisprudenciales de los jueces y magistrados, que son los inferiores jerárquicos (A quo) de los Consejeros de Estado, al ser un precedente. La indemnización de perjuicios inmateriales, en especial morales en materia de P.I.J.D.L., ha evolucionado hasta el punto de fijarse unas tablas con criterios verdaderamente objetivos, similares a las usados por la ley para la indemnización por pérdida de capacidad laboral (tablas de punto), lo anterior, creemos no ha sido una decisión acertada por parte del C.D.E., esto se debe a que solamente tener en cuenta este tipo de planteamientos objetivos para tomar decisiones puede llevar a fallos contradictorios y discriminatorios al tratar de medir con el mismo rasero situaciones bastante disímiles y condicionar de manera muy especial al juez quien posee 
la inmediatez para resolver según su buen juicio, el quantum indemnizatorio, sin embargo este sacrificio comporta una mayor seguridad jurídica al saber prima facie cual es la posible indemnización que podría ser obtenida.

Desde una perspectiva social, es muy importante, estudiar la reparación de los perjuicios que existen en materia de P.I.J.D.L., dado que en este tipo de casos, las víctimas, son personas inocentes que tuvieron que sufrir el sistema carcelario Colombiana que presenta cárceles con hacinamiento y además que se crean graves problemas en el proyecto de vida de quien la sufre, así como un profundo sufrimiento, que debe ser de ser en lo posible restablecido de manera integral por el Estado, con una compensación no solo en dinero, sino integral, que puede hacer la diferencia entre un Estado social de derecho, o un gobierno autoritario.

Desde una mirada académica, es importante resaltar que deben modificarse los criterios para determinar la reparación de perjuicios en materia de P.I.J.D.L., especialmente el daño moral, toda vez que el C.D.E. adoptó una decisión que comporta unos intereses que parecieran obedecer más a la necesidad de poder establecer una política fiscal efectiva, y de un mejor clima de seguridad jurídica, pero sacrificando la proporcionalidad en la indemnización que debe realizarse a las personas privadas injustamente de su libertad, evitando su reparación integral, y estando en contra vía de los derechos que estos tienen consagrados en los artículos 2 y 90 de la constitución política de Colombia [20], [21], [22].

La Jurisprudencia de Unificación de perjuicios inmateriales en P.I.J.D.L., anteriormente reseñada, propone de manera clara criterios objetivos para la tasación de perjuicios morales en materia de Privación Injusta, en este sentido se tiene que el juez debe respetar o estarse a lo decidido por este precedente jurisprudencial, que si bien no prohibió totalmente el principio de arbitrio iuris si lo limitó de una manera muy importante, por tal motivo, debemos establecer cuáles son los criterios que permitirán dar con una solución jurídica si se permite "justa" o "equitativa" ante casos similares [23], [24].

Se considera que se deben establecer criterios mixtos, es decir, objetivos y subjetivos, que le permitan al juez determinar de una manera precisa una indemnización similar o armónica ante casos similares aun acudiendo al arbitrio iuris pero que se encuentre regulado o enmarcado en ellos, producto de una reevaluación de los existentes, como la única posibilidad de respetar verdaderamente los derechos constitucionales de las víctimas de P.I.J.D.L.

Por lo antes anotado, se sostiene que NO se encuentran garantizados los derechos fundamentales de las victimas a una reparación integral en el desarrollo de la Jurisprudencia del C. D. E. en Materia de Perjuicios Inmateriales en P.I.J.D.L.

\section{Referencias}

[1] M. Aguiar, El daño especial como régimen aplicable para endilgar res-ponsabilidad al Estado por privación injusta de la libertad, Bogotá: Universidad Sergio Arboleda, 2012

[2] Constitución política de Colombia [Const.] 2da Ed. Legis, 1991

[3] R. Alexy, Teoría De Los Derechos Fundamentales, Madrid: Centro De Estudios Constitucionales Madrid, 1993

[4] Congreso de Colombia, Ley 270 de 1996. [En línea]. Disponible en: http://www. secretariasenado.gov.co/senado/basedoc/ ley_0270_1996.html 
La indemnización de perjuicios inmateriales en materia de privación injusta de la libertad en la jurisprudencia de unificación del Consejo de Estado

\section{2}

[5] C. Guerra, Yáñez, Método, Metodología Y Técnicas De La Investigación Aplicada Al Derecho, Bogotá D.C: Grupo Editorial Ibáñez, 2014

[6] E. Gil, Responsabilidad extracontractual del Estado (5a ed.), Bogotá: Temis S.A, 2011

[7] Consejo de Estado. Sala de lo Contencioso Administrativo. Sección Tercera. Sentencia. Expediente 1482, 1976

[8] W. Ruiz, La Responsabilidad del Estado y sus Regímenes, Bogotá: Ecoe Ediciones, Tercera Edición, 2016

[9] C. Duque, "La responsabilidad del Estado y de los jueces en Colombia y en España, a la luz de los principios del código iberoamericano de ética judicial”, Revista Vía Inveniendi et Iudicandi, no. 11, 2010

[10] C.D.E. Sala de lo Contencioso Administrativo, S.T, Sala Plena, Consejero ponente: Hernán Andrade Rincón (E), Bogotá, D.C., veintiocho (28) de agosto de dos mil catorce (2014), Radicación número: 68001-23-31-000-200202548-01(36149), Actor: José Delgado Sanguino Y Otros, Demandado: Dirección Ejecutiva de Administración Judicial Referencia: Apelación Sentencia - Acción De Reparación Directa. [En línea]. Disponible en: http://190.24.134.67/ documentos/boletines/151/S3/68001-23-31000-2002-02548-01(36149)\%20(1).pdf

[11] J. Calderón, La reparación integral en la jurisprudencia de la Corte Interamericana de Derechos Humanos: estándares aplicables al nuevo paradigma mexicano, México: Instituto de Investigaciones Jurídicas, 2013

[12] J.C Henao, El Daño, Bogotá: Editorial Universidad Externado de Colombia, 2001

[13] C. Jurado, G. Londoño y L. Toro L, "La responsabilidad extracontractual del Estado frente a la privación injusta de la libertad bajo el principio de in dubio pro reo", Nuevo Derecho, vol. 7, no. 9. pp. 45-57, 2011

[14] Corte Constitucional, Sentencia C 037 de 1996, Magistrado ponente: Vladimiro Naranjo Meza HERNÁN ANDRADE RINCÓN (E), Ref.: P.E.-008 Revisión constitucional del proyecto de ley número 58/94 Senado y 264/95 Cámara, "Estatutaria de la Administración de Justicia". [En línea]. Disponible en: http://www.corteconstitucional.gov.co/ relatoria/1996/C-037-96.htm

[15] D. Rueda Prada, "La indemnización de los perjuicios extrapatrimoniales en la jurisdicción de lo contencioso administrativo de Colombia", Tesis de Maestría en Derecho, Universidad del Rosario, 2014

[16]C.D.E. Sala de lo Contencioso Administrativo,S.T. Subsección C Consejero Ponente: Jaime Orlando Santofimio Gamboa. Bogotá, D.C., veintiocho (28) de enero de dos mil quince (2015). [En línea]. Disponible en: http:/consejodeestado.gov.co/documentos/ sentencias/05001233100020020348701.pdf

[16] M. García, "La libertad como derecho", Revista de la Facultad de Derecho de México, número especial, 2009. [En línea]. Disponible en:https://revistas-colaboracion.juridicas. unam.mx/index.php/rev-facultad-derecho-mx/ article/view/30129/27203

[17]Corte Constitucional, Sentencia de Constitucionalidad no 370/06 de Corte Constitucional, 18 de Mayo de 2006. Ponente: Manuel Jose Cepeda Espinosa Jaime Cordoba Triviño Rodrigo Escobar Gil Marco Gerardo Monroy Cabra Alvaro Tafur Galvis Clara Ines Vargas Hernandez. Fecha de Resolución: 18 de Mayo de 2006, 2006. [En línea]. Disponible en: https://corte-constitucional.vlex.com.co/vid/43624722 
[18] Corte Interamericana de Derechos Humanos. Caso Gangaram Panday Vs. Surinam, Sentencia de 21 de enero de 1994, 1994. [En línea]. Disponible en: http://www.corteidh.or.cr/docs/ casos/articulos/seriec_16_esp.pdf

[19] O. Bernal Payares, "Evolución del proceso administrativo desde los orígenes de la revolución industrial y su fundamento como una función del administrador", Enfoque Disciplinario, vol. 2, no. 1, pp. 1-14, 2017

[20] S.Y. García Salazar, J.F. Rojas-Ovalle y E.J. Barrientos Monsalve, "Alcance de las responsabilidades de las fiscalías de Venezuela y Colombia en la franja fronteriza estudio de caso por homicidios", Mundo Fesc, vol. 8, no. 16, pp. 78-85, ene. 2019

[21] A. Castro, Economía, salud, desarrollo humano e innovación en el desarrollo sustentable", Conocimiento global, vol. 3, no. 1, pp. 1-13, 2018

[22] E. Alzamora, "El poder del conocimiento y de la información como generador de valor en las organizaciones", Conocimiento global, vol. 3, no. 1, pp. 14-29, 2018

[23] I.C. Tinoco Marquina y L.E. Frías Reyes, "El sistema acusatorio adversarial mexicano desde la teoría de la justicia de Michael Sande", Mundo Fesc, vol. 7, no. 14, pp. 17-26, abr. 2018.

[24] A. Caballero Tovío, "Grado de articulación de las estrategias consignadas en el Plan Nacional de Desarrollo 2014-2018 con la situación del sector industrial colombiano", Enfoque Disciplinario, vol. 1, no. 1, pp. 14-20, 2016 